\title{
Infecção pelo virus linfotrópico de células T humanas e transmissão vertical em gestantes de estado da Região Centro-Oeste do Brasil
}

\author{
T-cell leukemia virus infection in pregnant women in a Central-Western state of Brazil
}

Ernesto Antonio Figueiró-Filho ${ }^{1}$, Alessandro Henrique Antunes Lopes ${ }^{2}$, Flávio Renato de Almeida Senefonte ${ }^{2}$, Virgilio Gonçalves de Souza Júnior ${ }^{3}$, Carlos Augusto Botelho ${ }^{3}$, Geraldo Duarte ${ }^{4}$

\section{RESUMO}

Objetivos: avaliar a prevalência, características epidemiológicas (idade e procedência) e a taxa de transmissão vertical da infecção pelo HTLV I/II em gestantes submetidas à triagem pré-natal de acordo com o Programa de Proteção à Gestante do Estado de Mato Grosso do Sul. Métodos: estudo descritivo transversal que incluiu 32.512 gestantes submetidas à triagem prénatal no período de novembro de 2002 a outubro de 2003. Todas as gestantes da amostra foram submetidas aos testes sorológicos pelo método ELISA para o diagnóstico da infecção pelo HTLV, sendo os casos positivos confirmados pelos métodos Western blot e/ou PCR. O diagnóstico neonatal de infecção congênita foi realizado pela pesquisa de anticorpos antiHTLV I/II confirmados por Western blot e PCR. A relação entre as variáveis (idade e procedência) foi avaliada pelo teste do $\chi^{2}$, em tabelas de dupla entrada, considerando $\mathrm{p}<0,05$ para rejeição das hipóteses de nulidade (não existência da associação entre a idade materna e infecção pelo HTLV I/II e associação entre procedência e positividade para a infecção pelo HTLV I/II.). Resultados: encontrou-se prevalência de $0,1 \%$ de gestantes infectadas pelo HTLV I/II (37) dentre as 32.512 pacientes triadas. A média de idade das gestantes infectadas pelo HTLV foi de 25,4 $\pm 6,4$ anos, sendo que houve predomínio de pacientes procedentes do interior do estado $(78,4 \%)$. Não houve associação da idade com faixa etária materna e procedência. Apenas 8 (21,6\% da amostra) recém-nascidos foram avaliados quanto à presença da infecção congênita pelo HTLV I/II, todos com infecção congênita confirmada. Apenas 1 recém-nascido (9\%) recebeu amamentação natural. Conclusões: a prevalência da infecção pelo HTLV I/II em gestantes sul-matogrossenses foi menor que os valores encontrados em estudos com gestantes de países endêmicos. No entanto, esteve próximo às taxas encontradas em países considerados não endêmicos e em alguns estudos brasileiros. A transmissão vertical ocorreu em 100\% da amostra avaliada, mesmo a amamentação sendo proscrita. Verificou-se a necessidade de aprimorar o seguimento das gestantes e seus recém-nascidos no estado, uma vez que a minoria dos recém-nascidos foram investigados quanto à ocorrência de transmissão vertical do HTLV.

PALAVRAS-CHAVE: Infecções por HTLVI; Infecções por HTLVII; Complicações infecciosas na gravidez; Gravidez; Infecção congênita

\section{ABSTRACT}

Purpose: to evaluate the prevalence, epidemiological profile (age and origin) and vertical transmission rate of HTLV I/II infection in pregnant women screened by the Pregnant Protection Program of the State of Mato Grosso do Sul - Brazil. Methods: it is a descriptive and transversal study of 32,512 pregnant women submitted to a prenatal screening from November 2002 to October 2003. HTLV I/II infection was diagnosed in all pregnant women by ELISA, confirmed by Western blot and PCR. Congenital HTLV infection was investigated by ELISA test, Western blot and PCR performed on the child's blood sample. The associations between data (age, origin and HTLV infection) were statistically analyzed by the $\chi^{2}$ test considering $\mathrm{p}<0.05$ to reject the null hypothesis. Results: a prevalence of $0.1 \%$ (37) $0.1 \%$ HTLV I/II among 32,512 pregnant women was found. The mean age of the infected women was $25.4 \pm 6.4$ years, and $78.4 \%$ of them were from other areas than the capital. There was no association between maternal age and the patients' origin and infection. In all the eight evaluated newborns, which represented $21.6 \%$ of the sample, HTLV I/II serum antibodies were found. Only one newborn infant was

Trabalho realizado no Departamento de Gineco-Obstetrícia da Faculdade de Fundação Medicina da Universidade Federal de Mato Grosso do Sul FUFMS - Campo Grande (MS) - Brasil.

1 Professor do Departamento de Ginecologia e Obstetrícia do Centro de Ciências Biológicas e da Saúde da Fundação Universidade Federal de Mato Grosso do Sul - FUFMS - Campo Grande (MS) - Brasil.

2 Acadêmicos do Curso de Medicina da Fundação Universidade Federal de Mato Grosso do Sul - FUFMS - Campo Grande (MS) - Brasil.

3 Responsáveis técnicos pelo Programa de Proteção à Gestante de Mato Grosso do Sul - Instituto de Pesquisa, Ensino e Diagnóstico - APAE - Campo Grande (MS) - Brasil.

4 Professor Titular de Obstetrícia do Departamento de Ginecologia e Obstetrícia da Faculdade de Medicina de Ribeirão Preto, Universidade de São Paulo - USP - Ribeirão Preto (SP) - Brasil.

Correspondência: Ernesto Antonio Figueiró-Filho

Rua Amazonas, 649 - Bairro São Francisco - 79010-060 - Campo Grande - MS - Fones: (67) 3029-2862 / (67) 325-7829 - e-mail: eafigueiro@uol.com.br

Recebido em: 15/3/2005 Aceito com modificaçōes em: 15/12/2005 
breast-fed. Conclusions: HTLV I/II prevalence among pregnant women of the State of Mato Grosso do Sul - Brazil was lower than the rates reported by endemic HTLV countries. This rate was almost the same as that described for non-endemic areas and in some Brazilian reports. The vertical transmission rate of HTLV I/II was $100 \%$, in spite of breast-feeding having been proscribed. Improving the follow-up of the pregnant women and their newborns in the State is mandatory, since only a few infants were investigated.

KEYWORDS: HTLVI infections; HTLVII infections; Pregnancy complications, infectious; Pregnancy; Congenital infection

\section{Introdução}

Está suficientemente demonstrado que algumas infecções durante à gravidez são causas de insucessos perinatais, como abortamentos, óbitos fetais, prematuridade, malformações congênitas e atraso do desenvolvimento psicomotor. Outra condição grave é a infecção adquirida verticalmente, que pode tornar-se crônica e empobrecer o prognóstico do recém-nascido. Dentre estas, encontra-se o vírus linfotrópico de células $\mathrm{T}$ humanas (HTLV).

O HTLV é um retrovirus da familia Retroviridae à qual pertence também o vírus da imunodeficiência adquirida humana. Divide-se em HTLV tipo I e HTLV tipo II. Possui tropismo por linfócitos T, nos quais produz infecção. Enquanto o HTLV-I infecta preferencialmente os linfócitos $\mathrm{CD}^{+}$, o HTLV-II infecta os linfócitos $\mathrm{CD}^{+}$. Ambos provocam infecção crônica, com período de latência longo (10 a 60 anos). O HTLV-I está comprovadamente associado à leucemia/linfoma de células $\mathrm{T}$ do adulto, cujo risco de aparecimento é de 2 a 4\%, e à doença neurológica crônica denominada paraparesia espástica tropical, também denominada mielopatia associada ao HTLV, que surge em menos de $1 \%$ dos infectados ${ }^{1}$. Outras doenças associadas são dermatite infecciosa em crianças, uveítes e menos comumente artralgias e polimiosite ${ }^{2}$. Quanto ao HTLV-II, ainda não foi definida sua associação com doenças humanas até o presente ${ }^{1,3}$.

O HTLV-I apresenta distribuição mundial, sendo endêmico no Japão, Caribe, África, América do Sul e ilhas da Melanésia. Estima-se que 15 a 20 milhões de pessoas estão infectadas pelo HTLV-I no mundo. As taxas de soroprevalência variam de 1 a $10 \%$ em grupos populacionais da Argentina, Brasil, Colômbia, Peru e países caribenhos como Guadalupe, Jamaica, Martinique e Trinidad e Tobago $^{2}$. A prevalência varia conforme a região geográfica, o grupo étnico e/ou racial e a subpopulação de risco ${ }^{1}$. Exibe aumento da soroprevalência com a idade, sendo mais elevada em mulheres, disparidade mais acentuada após os 40 anos de ida$\mathrm{de}^{3}$. No Brasil, o HTLV está presente em todos os estados onde foi pesquisado, com prevalências de
0,08\% em Manaus e Florianópolis, 0,33\% no Recife e Rio de Janeiro, 0,4\% em São Paulo e 1,35\% em Salvador ${ }^{4}$. Entre imigrantes japoneses de Campo Grande (MS) a taxa esteve em $10 \%{ }^{4}$. Estima-se que haja aproximadamente 2,5 milhões de pessoas infectadas pelo HTLV-I no Brasil, o que o torna o país com o maior número absoluto de casos ${ }^{3}$.

O HTLV-II é endêmico em alguns grupos populacionais da América e certas regiões da Áfri$\mathrm{ca}^{5}$. O HTLV-II está também presente no Brasil, sendo significativa a sua prevalência entre populações indigenas ${ }^{3}$.

Pode ocorrer transmissão do HTLV I/II por três vias: materno-infantil (principalmente por meio da amamentação prolongada), contato sexual e transmissão parenteral (componentes celulares sanguíneos contaminados e uso de seringas contaminadas) ${ }^{2}$. Quanto à transmissão por contato sexual, é maior a ocorrência da transmissão do homem para a mulher, sendo esta de $60,8 \%$, e rara da mulher para o homem, que é de $0,4 \%{ }^{4}$. A via básica de transmissão vertical (TV) do HTLV, tanto para o tipo I quanto para o tipo II, é a amamentação natural, podendo ocorrer ainda por via transplacentária ou hematogênica, contaminação do feto no canal do parto, por via ascendente ou contato íntimo entre a mãe e a criança $a^{4,6}$. Contudo, dentre as vias alternativas de transmissão, as mais prováveis são a transplacentária e a contaminação no canal do parto ${ }^{4,6}$.

O diagnóstico da infecção pelo vírus HTLV-I é feito em duas etapas: triagem e confirmação ${ }^{3}$. Como triagem para a infecção são utilizados os testes sorológicos, que testam a presença de anticorpos contra o vírus (ELISA ou aglutinação). Para confirmação, pode-se utilizar um teste sorológico, o Western blot, ou então a técnica de reação em cadeia de polimerase (PCR), que detecta diretamente o material genético viral e possui elevada sensibilidade e especificidade. Esta caracteristica faz da reação de PCR o método de escolha para avaliação da transmissão neonatal ${ }^{3}$. Além de confirmar a infecção, estes testes sorológicos são capazes de discriminar entre infecção pelo HTLV-I e HTLV-II.

Objetivou-se com o presente estudo avaliar a prevalência, as características epidemiológicas 
(idade e procedência) e a taxa de TV da infecção pelo HTLV I/II em gestantes do estado de Mato Grosso do Sul.

\section{Métodos}

Estudo descritivo e transversal realizado a partir de amostras provenientes de 32.512 gestantes submetidas à triagem pré-natal no período de novembro de 2002 a outubro de 2003, em todo o estado de Mato Grosso do Sul. Esta triagem é realizada pelo Programa de Proteção à Gestante de Mato Grosso do Sul (PPG-MS), desde novembro de 2002, abrangendo todos os municipios e 98\% das mulheres grávidas do estado usuárias do Sistema Único de Saúde (SUS) (porcentagem em relação ao total estimado de gestantes do estado no período). Este programa faz investigação sorológica de 10 infecções (HIV, hepatite B, hepatite C, HTLV, toxoplasmose, doença de Chagas, herpes simples, sífilis, citomegalovírus e rubéola) e da fenilcetonúria materna, por meio da técnica de papel filtro. A amostra populacional do estudo incluiu todas as gestantes triadas no Estado no período de um ano (novembro de 2002 a outubro de 2003).

A gestante, ao iniciar o acompanhamento médico pré-natal, recebe solicitação da coleta de gota de sangue digital no papel filtro, o qual é enviado do posto de coleta até o Laboratório do Instituto de Pesquisa, Ensino e Diagnóstico (IPED) da APAE de Campo Grande-MS, conveniado à Secretaria Estadual de Saúde, com apoio das secretarias municipais de saúde do estado de Mato Grosso do Sul. Deste laboratório partem os resultados para os respectivos centros de triagem, solicitando nova coleta se os testes forem positivos ou indeterminados. Neste caso, a nova coleta, com amostra de soro, destina-se ao Laboratório Central (LACEN) da Fundação Serviços Estaduais de Saúde para confirmação do primeiro resultado.

A técnica do papel filtro consiste na coleta de sangue das pacientes, proveniente da polpa digital ou de punção venosa, com deposição no papel filtro em área previamente demarcada. Após secagem da amostra (até 4 horas), o papel filtro é enviado ao laboratório IPED-APAE em Campo Grande, não ultrapassando período superior a 24 horas após a coleta. Após chegada ao laboratório, a amostra de sangue é ressuspendida, e então processada pelos testes sorológicos-padrão para cada patologia. Pelo controle de qualidade interno do laboratório IPED-APAE, em momento diverso ao realizado no presente estudo, verificou-se que a sensibilidade e a especificidade no papel filtro fo- ram semelhantes aos testes realizados no soro, para todas infecções pesquisadas. A sensibilidade e a especificidade do método ELISA empregado na triagem da infecção pelo HTLV por meio da técnica do papel filtro corresponderam a 100 e 99,9\%, respectivamente, semelhantes às obtidas quando utilizado soro.

A triagem da infecção pelo HTLV I/II foi realizada em todas as gestantes atendidas pelo SUS no estado que ingressaram no acompanhamento pré-natal no período citado, pelo método ELISA utilizando amostra de sangue do papel filtro, para pesquisa de anticorpos contra este vírus. Os casos positivos e indeterminados foram submetidos ao teste ELISA no soro para confirmação. Havendo positividade pelo método ELISA, foi praticada nova coleta para realização de testes confirmatórios mais específicos, sendo utilizadas a técnica do Western blot, realizada no próprio laboratório IPED da APAE, e/ou a PCR, dependendo da disponibilidade deste último teste (PCR) no momento da confirmação da infecção.

As gestantes com infecção pelo HTLV I/II confirmada e os respectivos recém-nascidos foram acompanhados nas redes municipais e/ou estaduais de saúde. Para as crianças acompanhadas pela pediatria do Centro Multidisciplinar de Atendimento à Saúde (CAMS-APAE) em Campo Grande (MS) realizou-se o protocolo de diagnóstico de infecção neonatal, sendo utilizado para o HTLV, os métodos ELISA e Western blot aos seis meses de vida. Havendo positividade, em seguida solicitou-se pesquisa do DNA viral com técnica do PCR, para confirmação da infecção. Para o cálculo da TV foram levantados os dados referentes aos resultados dos testes diagnósticos de infecção congênita realizados nestes recém-nascidos.

Todas as informações utilizadas no estudo foram obtidas diretamente com os centros de saúde responsáveis pelo acompanhamento pré-natal destas pacientes, por meio da pesquisa em prontuários e por contato telefônico com as gestantes, mediante protocolo de pesquisa adotado, e após aprovação pelo Comitê de Ética em Pesquisa da Universidade Federal de Mato Grosso do Sul.

A avaliação da variável idade foi realizada pela comparação de médias, ao passo que a associação entre algumas variáveis categóricas como procedência foi avaliada pelo teste do $\chi^{2} \mathrm{em}$ tabelas de contingência de dupla entrada. Quando em tabela 2 × 2 uma variável obteve valor inferior a cinco, foi utilizado o teste exato de Fisher bicaudado para descrição do valor de p. Foi aceito $\mathrm{p}<0,05(95 \%)$ como limite para aceitar significância. 


\section{Resultados}

Dentre a população de 32.512 gestantes triadas, houve soropositividade para pesquisa de anticorpos contra o HTLV I/II em 37 pacientes, resultando em $0,1 \%$ de prevalência da infecção em gestantes do estado de Mato Grosso do Sul. Em quatro $(11 \%)$ pacientes a infecção foi confirmada pelo Western blot, em $21(57 \%)$ por meio da PCR e em quatro $(11 \%)$ por ambos os métodos. Nas pacientes restantes (oito) somente foi realizado o diagnóstico pelo método ELISA no soro. Não houve casos em que o teste ELISA no soro fosse reagente e os testes confirmatórios negativos para a pesquisa do HTLV (falso-positivos).

A média de idade das gestantes portadoras

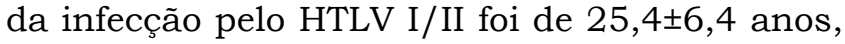
variando de 17 a 45 anos, havendo predominância da faixa entre 20 e 29 anos. Contudo, não houve associação estatisticamente significativa $(p=0,38)$ entre faixa etária e infecção materna pelo HTLV (Tabela 1). A maioria das gestantes soropositivas para o HTLV I/II procedia das cidades do interior do estado $(78,4 \%)$, sendo que da população total de gestantes triadas, $75,2 \%$ provinham do interior (Tabela 2). Não houve associação estatisticamente significativa $(\mathrm{p}=0,8)$ entre a procedência das gestantes e a prevalência da infecção pelo HTLV (Tabela 2).

\begin{tabular}{|c|c|c|c|}
\hline Idade & $\begin{array}{l}\text { Sorologia } \\
\text { positiva }\end{array}$ & $\begin{array}{c}\text { Sorologia } \\
\text { negativa }\end{array}$ & Total \\
\hline $15-19$ anos & $5(13,5 \%)$ & $9.093(28,8 \%)$ & $9.098(28,8 \%)$ \\
\hline 20-29 anos & $22(59,5 \%)$ & $17.297(54,8 \%)$ & $17.319(54,8 \%)$ \\
\hline 30-39 anos & $7(18,9 \%)$ & $4.786(15,1 \%)$ & $4.793(15,1 \%)$ \\
\hline 40-49 anos & $3(8,1 \%)$ & $396(1,3 \%)$ & $399(1,3 \%)$ \\
\hline Total & $37(100 \%)$ & $31.572(100 \%)$ & $31.609(100 \%)$ \\
\hline
\end{tabular}

Tabela 2 - Relação entre a sorologia ELISA para o HTLV e a procedência das gestantes.

\begin{tabular}{lccr}
\hline & $\begin{array}{c}\text { Sorologia } \\
\text { positiva }\end{array}$ & $\begin{array}{c}\text { Sorologia } \\
\text { negativa }\end{array}$ & \multicolumn{1}{c}{ Total } \\
\hline Capital & $8(21,6 \%)$ & $8037(24,7 \%)$ & $8045(24,7 \%)$ \\
Interior & $29(78,4 \%)$ & $24438(75,3 \%)$ & $24467(75,3 \%)$ \\
Total & $37(100 \%)$ & $32475(100 \%)$ & $32512(100 \%)$ \\
\hline
\end{tabular}

$\chi^{2}=0,06$ (correção de Yates); $p=0,8$; odds ratio $=0,84$ (IC 95\%: 0,38-1,83).

Com o uso da técnica do PCR pôde-se confirmar a infecção e distinguir entre os tipos virais, sendo que em $52 \%$ das gestantes foi detectado o HTLV tipo I e em $48 \%$, o tipo II.
Observou-se a ocorrência de infecção pelo HIV em 5,4\% das gestantes portadoras da infecção pelo HTLV I/II, taxa que é de apenas $0,2 \%$ no total de gestantes triadas.

Em relação ao seguimento pós-natal dos recém-nascidos das 37 mães confirmadas portadoras da infecção pelo HTLV I/II no período, observou-se que a maioria $(75 \%)$ das crianças nasceu de parto normal, com idade gestacional média de $40,1 \pm 1,75$ semanas, tendo, em média, o peso de $3359 \pm 321$ gramas e estatura média de $50,33 \pm 1,5 \mathrm{~cm}$. Dos recém-nascidos, $89 \%$ eram do sexo masculino, e apenas $9 \%$ de todas as crianças receberam aleitamento natural, por opção materna.

Em apenas oito $(21,6 \%)$ foi avaliada a ocorrência da TV. Nas demais 29 crianças $(88,4 \%)$ não foram realizados testes diagnósticos para infecção congênita pelo HTLV I/II. Dentre as crianças investigadas, houve positividade para os anticorpos anti-HTLV I/II em todas elas. Dentre estas, sete foram submetidas ao teste confirmatório por meio do PCR, havendo positividade em todos os casos, resultando em $100 \%$ de TV.

\section{Discussão}

A taxa de prevalência da infecção pelo HTLV no estado de Mato Grosso do Sul $(0,1 \%)$ mostrouse inferior às taxas observadas nos países originalmente endêmicos (de maior prevalência) para a infecção, contudo próxima ao encontrado em estudos brasileiros e de países de menor prevalência. Em populações endêmicas para a infecção, as taxas de prevalência são mais elevadas, como no Japão $(3,7 ; 5,4 \%)^{7,8}$, Guiana Francesa $(4,4 \%)^{9}$, Peru $(2,3 \%)^{10}$ e Jamaica $(2 \%)^{11}$. No entanto, em países não endêmicos, as taxas de prevalência são acentuadamente menores, como na Espanha $(0,064 \%)^{12}$ e Reino Unido $(0,39 \%)^{13}$.

Em outros estudos de soroprevalência da infecção pelo HTLV nacionais, obtiveram-se resultados em gestantes na Bahia $(0,84 \%)^{14}$ e Botucatu (SP) $(0,1 \%)^{15}$, que mostram proximidade com a taxa de prevalência encontrada entre as gestantes sulmato-grossenses $(0,1 \%)$. A característica étnica/ racial da população do estado da Bahia, com grande proporção de indivíduos da raça negra, e o fato de ser o estado que possui a maior prevalência do HTLV no Brasil justificam a maior prevalência da infecção verificada entre as gestantes ${ }^{14}$.

A pesquisa sorológica de infecções com amostra de sangue em papel filtro constitui técnica inovadora e útil para triagem pré-natal, pois 
mantém a segurança dos testes séricos realizados (sensibilidade e especificidade semelhantes ao ELISA no soro), apresentando maior facilidade na coleta, transporte e manuseio do material colhido. A metodologia do papel filtro já é amplamente utilizada no Brasil, sendo divulgada através do teste do "pezinho" há mais de dez anos. O único ponto que talvez seja questionável quanto à utilização da técnica do papel filtro como método de rastreamento sorológico em massa no período prénatal, seria o maior custo da técnica em relação ao método tradicional.

Demonstra-se que a infecção pelo HTLV exibe taxa de prevalência variável com a idade, sendo maior nas gestantes mais idosas. Isto foi verificado por Tortevoye et al. ${ }^{16}$, que encontraram soroprevalência de $2,8 \%$ entre gestantes com idade inferior a 25 anos e 8,3\% entre gestantes com idade superior a 25 anos. No presente estudo verificou-se que a taxa de prevalência foi menor na faixa etária de 15 a 19 anos $(0,05 \%)$, mostrandose progressivamente mais elevada nas faixas superiores, principalmente acima dos 40 anos $(0,75 \%)$. No entanto, não houve associação significativa entre faixa etária e infecção materna pelo HTLV. A média de idade foi de 25,4 anos, próxima à média de 26,2 anos encontrada por Bittencourt et al. ${ }^{14}$ em gestantes baianas. Segundo Ades et al. ${ }^{5}$, o contato sexual é o primeiro modo de transmissão do HTLV entre mulheres em idade fértil, sendo pequena fração atribuída à amamentação, o que explica a baixa prevalência em pacientes mais jovens e o aumento da soroprevalência dependente da idade.

Merece destaque a associação entre a infecção pelo HIV e o HTLV encontrada na população estudada, devido à ocorrência de co-infecção em $5,4 \%$ das pacientes sendo, no entanto, esperada uma prevalência da infecção pelo HIV próxima à encontrada na população de gestantes triada $(0,2 \%)$. Esta associação positiva foi referida por Ades et al. ${ }^{5}$ no Reino Unido. Segundo estes, a elevada TV do HTLV em nutrizes que amamentam seus filhos por longo período justificaria a triagem pré-natal do HTLV em todas as gestantes, especialmente as infectadas pelo HIV 5 .

Verificamos entre as pacientes com a infecção confirmada pela PCR que em $52 \%$ das gestantes foi detectado o tipo viral I e em $48 \%$, o tipo II. Estes dados demonstram que os dois tipos virais são endêmicos na população de Mato Grosso do Sul. A triagem sorológica em doadores de sangue dos Estados Unidos também demonstrou ocorrência paralela dos dois tipos virais, sendo que aproximadamente $50 \%$ dos doadores apresentaram infecção pelo HTLV-II ${ }^{17,18}$.
Dentre as oito crianças nascidas de mães pertencentes à amostra e acompanhadas quanto à ocorrência de TV, todas foram reagentes na pesquisa de anticorpos contra o HTLV I/II pelo método sorológico ELISA. Em sete crianças foi realizada a PCR com seis meses de vida, confirmando a infecção em todos os casos. A criança restante não obteve a infecção confirmada, uma vez que a pesquisa sorológica não é o método mais indicado para diagnóstico da infecção neonatal, devido à persistência de anticorpos maternos circulantes no recém-nascido durante os primeiros meses de vida ${ }^{4}$.

Sabe-se que os títulos de anticorpos decrescem após o nascimento e persistem em $20 \%$ dos lactentes até os 6 meses de idade e, raramente permanecem positivos aos 12 meses $^{4}$. Considera que a maioria das crianças apresenta soroconversão aos 12 meses, sendo a idade ideal recomendada para o diagnóstico de infecção vertical pelo HTLV os 18 meses de vida. Outros autores afirmam que a soroconversão pode ocorrer mais tarde, aos 3 anos ou mais ${ }^{19,20}$. Em estudo com 27 crianças nascidas de mães HTLV-I soropositivas e confirmadas com PCR, somente $7 \%$ de crianças infectadas foram detectadas pela sorologia, em contraste com a taxa de $28 \%$ obtida quando se utiliza $\mathrm{PCR}^{4}$. Esta soronegatividade associada à PCR positiva pode ser explicada pelo longo período de latência do HTLV-I ${ }^{20}$. Justifica-se então a PCR como técnica de escolha para o diagnóstico da infecção neonatal ${ }^{3}$. O teste Western blot pode manter-se positivo na criança até 6 meses de idade, devido à presença de anticorpos maternos. Neste intervalo há desaparecimento de todas as bandas, havendo surgimento subseqüente de novas bandas após este período, relacionadas com a infecção nativa no lactente ${ }^{1}$.

A TV confirmada do HTLV no presente estudo, apesar do pequeno número de crianças analisadas, afetou todos os recém-nascidos testados de mães soropositivas e com infecção confirmada. Sabe-se que a taxa de TV varia de acordo com a ocorrência de aleitamento natural, o tempo de amamentação, níveis elevados de anticorpos maternos, a carga viral elevada, tempo de ruptura de membranas prolongado e baixo nível socioeconômico materno ${ }^{1,2,21}$. No Japão, as taxas variam de 15 a $25 \%{ }^{4}$. Em dois estudos desenvolvidos na Guiana Francesa, em crianças amamentadas naturalmente e nascidas de mães soropositivas para o HTLV, a taxa de TV foi de $10,6^{21}$ e $9,7 \%{ }^{9}$.

A amamentação é o meio mais freqüente de TV do HTLV-I. Entre as crianças jamaicanas, observaram-se $32 \%$ de soropositividade ao HTLV quando houve amamentação natural por mais de 
12 meses e $8 \%$ quando amamentadas por período menor que 12 meses $^{22}$. No entanto, quando os recém-nascidos são amamentados por curto período (menor que 7 meses) encontrou-se transmissão em 3,8\% deles, ao passo que entre os recémnascidos amamentados por longo período (maior que 7 meses), a taxa é de 25 e de $5,6 \%$ para recémnascidos com aleitamento artificial exclusivo.

Apesar da elevada taxa de TV encontrada, apenas 9\% (um paciente) das crianças infectadas receberam aleitamento natural materno. Esta criança foi amamentada por periodo superior a 6 meses. Com isso pode-se considerar que, nesta amostra, o aleitamento natural não foi a forma de TV do HTLV. Nestes casos a provável via de infecção é a transplacentária ou a contaminação através do canal do parto ${ }^{6}$. Na literatura existem estudos demonstrando que crianças não amamentadas naturalmente demonstram-se infectadas em freqüências que variam de 4 a $14 \%{ }^{6}$.

A maioria dos recém-nascidos $(75 \%)$ nasceu de parto normal. Este pode ser fator relacionado a mais elevada TV do virus na ausência do aleitamento natural destas crianças. O mecanismo relacionado à transmissão intraparto seria a ocorrência de microtransfusões materno-fetais durante o trabalho de parto, que resultariam em quebra da barreira placentária e transmissão do vírus ao feto, e o contato do feto com o sangue e secreções maternas em sua passagem pelo canal do parto ${ }^{6}$. No parto cesárea o risco destas microtransfusões é menor ${ }^{6}$, porém não há comprovação científica da redução da TV por meio da realização do parto cesáreo na infecção pelo HTLV ${ }^{6}$.

Pelo presente estudo pôde-se avaliar a infecção pelo HTLV I e II em gestantes sul-matogrossenses, encontrando-se que a soroprevalência $(0,1 \%)$ foi inferior aos valores encontrados em estudos desenvolvidos com gestantes em paises endêmicos da infecção, como Japão, Jamaica e Guiana Francesa. No entanto, esteve próxima às taxas encontradas em países considerados não endêmicos, como o Reino Unido e Espanha, e em alguns estudos brasileiros (São Paulo e Bahia). A TV do HTLV I/II, ocorrida em todos os recém-nascidos pesquisados, demonstrou-se mais elevada do que em outros estudos. Os autores concordam que a taxa de TV demonstrou-se muito elevada em relação à descrita na literatura, o que pode ser atribuído ao reduzido número de neonatos pesquisados e à TV transplacentária e intrapartal, uma vez que apenas $9 \%$ dos neonatos foram amamentados.

Os dados revelaram insatisfatório o acompanhamento dos recém-nascidos, uma vez que uma minoria $(21 \%)$ deles foi investigada quanto à ocorrência de infecção congênita. Sabe-se que a identificação pré-natal de gestantes infectadas para orientar a suspensão da amamentação é medida fundamental para o controle da TV do vírus HTLV I/II, sendo o único método capaz de reduzi-la, em até $80 \%$. Isto torna válida a realização da triagem pré-natal de infecção pelo vírus HTLV I/II. Entretanto, esta intervenção requer adequado seguimento pós-natal dos recém-nascidos de gestantes infectadas, para que confirme o controle da TV do vírus e sejam validados os programas de rastreamento populacional como o aqui apresentado.

\section{Referências}

1. Veronesi R. HTLV e doenças associadas. In: Veronesi R, Focacci R, editores. Tratado de infectologia. 2a ed. São Paulo: Atheneu; 2002. p. 1310-25.

2. Kazanji M, Gessain A. Human T-cell lymphotropic virus types I and II (HTLV-I/II) in French Guiana: clinical and molecular epidemiology. Cad Saúde Pública. 2003;19(5):1227-40.

3. Carneiro-Proietti ABF, Ribas JGR, Catalan-Soares BC, Martins ML, Brito-Melo GEA, Martins-Filho OA, et al. Infecção e doença pelos vírus linfotrópicos humanos de células T (HTLV-I/II) no Brasil. Rev Soc Bras Med Trop. 2002;35(5):499-508.

4. Bittencourt AL. Vertical transmission of HTLV-I/II: a review. Rev Inst Med Trop São Paulo. 1998;40(4):245-51.

5. Ades AE, Parker S, Walker J, Edginton M, Taylor GP, Weber JN. Human T cell leukaemia/lymphoma virus infection in pregnant women in the United Kingdom: population study. BMJ. 2000;320(7248):1497-501.

6. Bittencourt AL, Sabino EC, Costa MC, Pedroso C, Moreira L. No evidence of vertical transmission of HTLV-I in bottle-fed children. Rev Inst Med Trop São Paulo. 2002;44(2):63-5.

7. Kashiwagi K, Furusyo N, Nakashima H, Kubo N, Kinukawa N, Kashiwagi S, et al. A decrease in mother-to-child transmission of human $\mathrm{T}$ lymphotropic virus type I (HTLV-I) in Okinawa, Japan. Am J Trop Med Hyg. 2004;70(2):158-63.

8. Oki T, Yoshinaga M, Otsuka H, Miyata K, Sonoda S, Nagata Y. A sero-epidemiological study on mother-to-child transmission of HTLV-I in southern Kyushu, Japan. Asia Oceania J Obstet Gynaecol. 1992;18(4):371-7.

9. Carles G, Tortevoye P, Tuppin P, Ureta-Vidal A, Peneau C, El Guindi W, et al. HTLV1 infection and pregnancy. J Gynecol Obstet Biol Reprod (Paris). 2004;33(1 Pt 1):14-20. 
10.Zurita S, Costa C, Watts D, Indacochea S, Campos $\mathrm{P}$, Sanchez J, et al. Prevalence of human retroviral infection in Quillabamba and Cuzco, Peru: a new endemic area for human $\mathrm{T}$ cell lymphotropic virus type 1. Am J Trop Med Hyg. 1997;56(5):561-5.

11. Dowe G, King SD, Smikle MF, Wynter HH, Chout R, Klaskala W. Prevalence of viral and bacterial sexually transmitted pathogens in Jamaican pregnant women. West Indian Med J. 1998;47(1):23-5.

12. Machuca A, Tuset C, Soriano V, Caballero E, Aguilera A, Ortiz de Lejarazu R, et al. Prevalence of HTLV infection in pregnant women in Spain. Sex Transm Infect. 2000;76(5):366-70.

13. Donati $M$, Seyedzadeh $H$, Leung $T$, Blott $M$, Zuckerman M. Prevalence of antibody to human T cell leukaemia/ lymphoma virus in women attending antenatal clinic in southeast London: retrospective study. BMJ. 2000;320 (7227):92-3.

14. Bittencourt AL, Dourado I, Bastos Filho P, Santos M, Valadao E, Alcantara LC, et al. Human T-cell lymphotropic virus type 1 infection among pregnant women in northeastern Brazil. J Acquir Immune Defic Syndr. 2001;26(5):490-4.

15. Olbrich Neto J, Meira DA. Soroprevalência de virus linfotrópico de células $\mathrm{T}$ humanas, vírus da imunodeficiência humana, sífilis e toxoplasmose em gestantes de Botucatu - São Paulo - Brasil: fatores de risco para vírus linfotrópico de células T humanas. Rev Soc Bras Med Trop. 2004;37(1):28-32.
16. Tortevoye P, Tuppin P, Peneau C, Carles G, Gessain A. Decrease of human T-cell lymphotropic virus type I prevalence and low incidence among pregnant women from a high endemic ethnic group in French Guiana. Int J Cancer. 2000;87(4):534-8.

17. Van Dyke RB, Heneine W, Perrin ME, Rudolph D, Starszak E, Woods T, et al. Mother-to-child transmission of human T-lymphotropic virus type II. J Pediatr. 1995;127(6):924-8.

18. Williams AE, Fang CT, Slamon DJ, Poiesz BJ, Sandler SG, Darr WF 2nd, et al. Seroprevalence and epidemiological correlates of HTLV-1 infection in U.S. blood donors. Science. 1988;240(4852):643-6.

19. Hino S, Katamine S, Miyata H, Tsuji Y, Yamabe T, Miyamoto T. Primary prevention of HTLV-I in Japan. Leukemia. 1997;11 Suppl 3:57-9.

20. Kusuhara K, Sonoda S, Takahashi K, Tokugawa K, Fukushige J, Ueda K. Mother-to-child transmission of T-cell leukemia virus type I (HTLV-I): a fifteenyear follow-up study in Okinawa, Japan. Int $\mathrm{J}$ Cancer. 1987;40(6):755-7.

21. Monplaisir N, Neisson-Vernant C, Bouillot M, DucDodon M, Ugarte E, Valette I, et al. HTLV-I maternal transmission in Martinique, using serology and polymerase chain reaction. AIDS Res Hum Retroviruses. 1993;9(9):869-74.

22. Ureta-Vidal A, Angelin-Duclos C, Tortevoye P, Murphy E, Lepere JF, Buigues RP, et al. Mother-tochild transmission of human T-cell-leukemia/ lymphoma virus type I: implication of high antiviral antibody titer and high proviral load in carrier mothers. Int J Cancer. 1999;82(6):832-6. 